\title{
Analysis of torque cam mechanism
}

\author{
Iryna Hren ${ }^{1,}$, Petr Hejma ${ }^{1}$, Štefan Michna ${ }^{1}$, Martin Svoboda ${ }^{1}$, Josef Soukup ${ }^{1}$ \\ ${ }^{1}$ Faculty of Pruduction Technology and Management Jan Evangelista Purkyně University in Ústí nad \\ Labem, Department of Machines and Mechanics, 400 96, Pausterova 1, Ústí n/L, Czech Republic
}

\begin{abstract}
The article deals with the process of torque camshaft at a constant speed. The method of release was determined by the normal force acting between the cam and the tappet. Subsequently, was expressed torque. A prerequisite for the calculations are a constant friction coefficient between the components of the mechanism and constant speed of the camshaft. Cam used for the purposes of this study generated polynomial lifting dependence. Part of this work is the calculation methodology lifting addiction. Course of torque is the conclusion presented on the values of the corresponding measuring station, which is the result of previous work on the subject.
\end{abstract}

Key words: cam, polynomial stroke, flat cam, hoist, torque.

\section{Introduction}

Cam mechanisms are an integral part of many machines. The cams are used as a generator of well-defined path in the so-called "hard" automation, also they are part of the fitness machines, which provide the required course of torque. By default, the cam mechanisms used for opening the valve of the internal combustion engine. This is also the most common use. From the above it is clear that cam mechanisms can have many configurations. This work deals with the arrangement of the cam mechanism, which is flat tappet is pressed against the surface of the cam disk using coiled torsion spring. An important parameter is the stroke of the cam dependence, which in this case assigned to the particular rotational angle position of the cam follower of the cam base circle. Cam base circle is the smallest circle which is circumscribed point of the cam profile and cam profile is the area that is in contact with the plunger. There are many approaches to the formation of lifting dependence. Due to the planned automation of calculation was chosen for this work approach, which was presented in 1952 Dudlym [1,2]. This is the definition of lifting dependence using algebraic polynomial (1).

$$
S_{n}=\sum_{i=0}^{n} \alpha_{i} \cdot \phi^{i}
$$

where $\alpha_{i}$ is the coefficients of the polynomial, $\varphi[\mathrm{rad}]$ the rotation angle of the cam and $n$ is an odd integer that is greater than 1. Yet unknown polynomial coefficients are calculated using boundary conditions at prominent points of the cam profile. This is about

\footnotetext{
* Corresponding author: hren@fvtm.ujep.cz

Reviewers: Zuzana Murčinková, Ján Vavro
} 
the points A and B on fig. 1, where the cam is shown in three positions. The first position is marked with index 1, point $B$ (active connection point on the base circle of the cam profile) lies on the $y$-axis and is valid $\varphi=0$. Index 2 is marked with the general position of the cam. Index 3 is marked with the position in which it reaches the tappet lift $z[\mathrm{~m}]$, point A lies on the y axis and $\varphi=\varphi_{2}$. The angle $\varphi_{2}$ is therefore the minimum angle needed to reach the stroke $z$. from the definition to the $n$-th degree polynomial is $n+1$ conditions are needed. To uniquely define the $n$-th degree polynomial that you need $n+1$ terms.

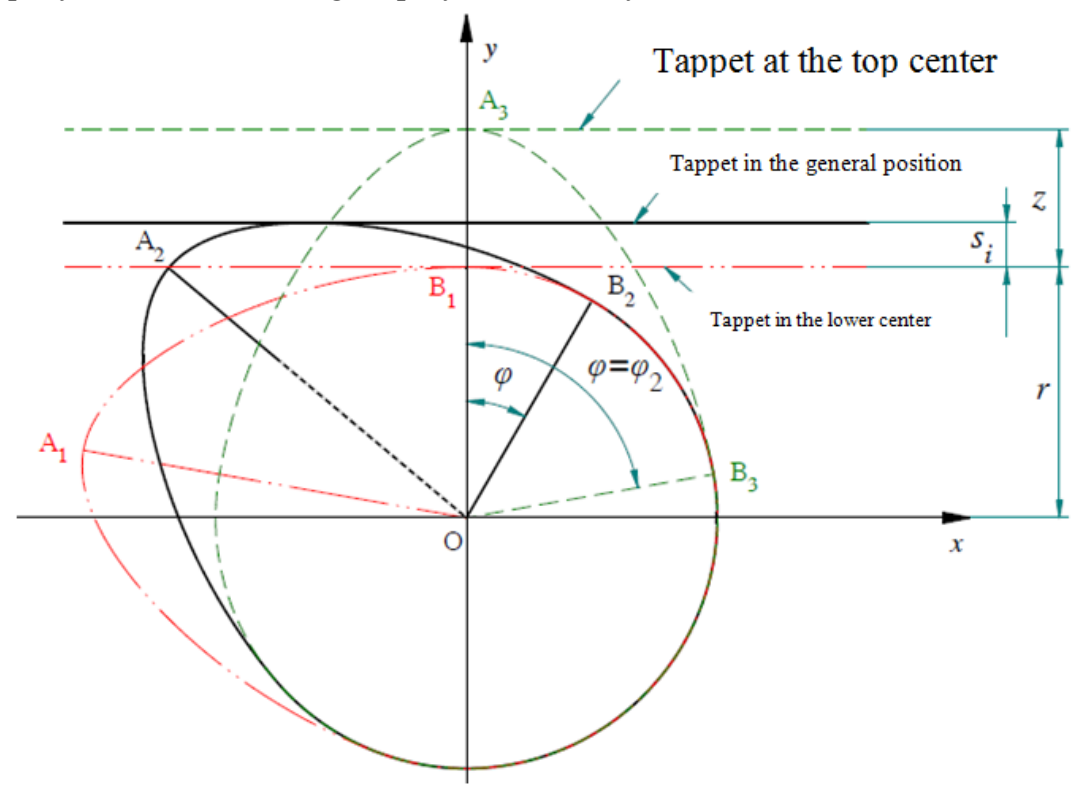

Fig. 1. The position of the cam

For the angle of rotation $\varphi=0$ (index 1 in Fig. 1) we introduce boundary conditions given by the relation (2).

$$
\frac{\mathrm{d}^{u} s_{n}(0)}{\mathrm{d} \phi^{u}}=0
$$

where $u$ is the order of the derivative that $u \in \mathbf{N}_{0} \wedge u \in\langle 0 ;(n-1) / 2\rangle$. Of these conditions implies that the coefficients of the polynomial $\alpha_{0}$ to $\alpha_{\frac{n-1}{2}}$ are equal to 0 . The form of the polynomial is then reduces to equation (3).

$$
s_{n}=\sum_{i=\frac{n+1}{2}}^{n} \alpha_{i} \cdot \phi^{i}
$$

The angle of rotation $\varphi=\varphi_{2}$ match the following boundary conditions.

$$
\begin{gathered}
s_{n}\left(\phi_{2}\right)=z \\
\frac{\mathrm{d}^{v} s_{n}\left(\varphi_{2}\right)}{\mathrm{d} \varphi^{v}}=0
\end{gathered}
$$


where $v$ is again the order of the derivative, for which the $v \in \mathbf{N} \wedge v \in\langle 1 ;(n-1) / 2\rangle$. To simplify the math, we will introduce the following variable.

$$
p=(n+1) / 2
$$

Substituting the boundary conditions (4), (5) into equation (3) form a system $p$ of equations $p$ unknowns that has a matrix notation in the following form.

$$
\mathbf{A} \cdot \mathbf{x}=\mathbf{b}
$$

where $\mathrm{A}$ is a square matrix of constants with the size $p, x$ is a column vector of unknown coefficients of the polynomial with $p$ rows, and $\mathrm{b}$ is the column vector of the right sides of dimension $p$. Index $e$ denote the serial number of the line and $f$ let's label the columns. The members of the matrix A are defined as constants programmer formula (8), where $e, f \in \mathbf{N} \wedge e, f \in\langle 1 ;(n+1) / 2\rangle$.

$$
a_{e f}=\varphi_{2}^{p+f-e} \prod_{k=1}^{e-1}(p+f-k)
$$

For $e=1$ is the first member of the right sides of the vector is given by (9).

$$
b_{1}=z
$$

For $e>1$ the remaining members of the vector $\mathrm{b}$ given by equation (10).

$$
b_{e}=0
$$

Members of the unknown vector is then defined by equation (11).

$$
x_{e}=\alpha_{p+e-1}
$$

Matrix equation (7) then has a solution (12).

$$
\mathbf{x}=\mathbf{A}^{-1} \mathbf{b}
$$

The proposed solution (12) using the inverse matrix computation is not from the perspective of computer time efficient, but clearly leads to the calculation of the unknown. The aim of this work is not solving the optimization equation system, but analysis of torque.

\section{Torque}

The following sections will be based methodology to calculate the torque[3-5]. For passive resistances are included in the mathematical model of the frictional forces between the cam and the tappet, between the tappet and the further conduit. First will be determined normal force between the cam and the tappet, subsequently will be expressed by the torque required to drive the mechanism. The calculation will be made by the method of release. A prerequisite is the constant angular velocity of the cam [6-8]. This paper deals only with the stroke, because during the course of work on the mechanism of the greatest strength. Stroke phase is thus decisive for the choice of a suitable propellant. Figure 2 is released tappet (linkages replaced bond strengths).

The cam rotates clockwise. The arrows indicated the forces acting on the plunger. $f_{k}[1]$, $(k=\{1,2,3\})$ the friction coefficient between the individual components and $N_{k}[\mathrm{~N}]$ 
$(k=\{1,2,3\})$ the normal force. $F_{p}[\mathrm{~N}]$ the spring force which prevents the plunger rebound from the cam profile during the stroke or the return of the plunger does not change direction, and is dependent on the stroke $s_{n}[\mathrm{~m}], F_{s}$ the inertia force of the plunger and materials related to it during the return stroke and changes direction. $F_{g}[\mathrm{~N}]$ the weight lifters and materials related to it, during the return stroke and does not change direction or size. Forces $N_{1}[\mathrm{~N}]$ and $N_{1} \cdot f_{1}$ when lifting or returning the plunger does not change direction. $a_{m}, b_{m}, d_{m}[\mathrm{~m}]$ are the lengthwise dimensions of the mechanism. The spring force is given by equation (13).

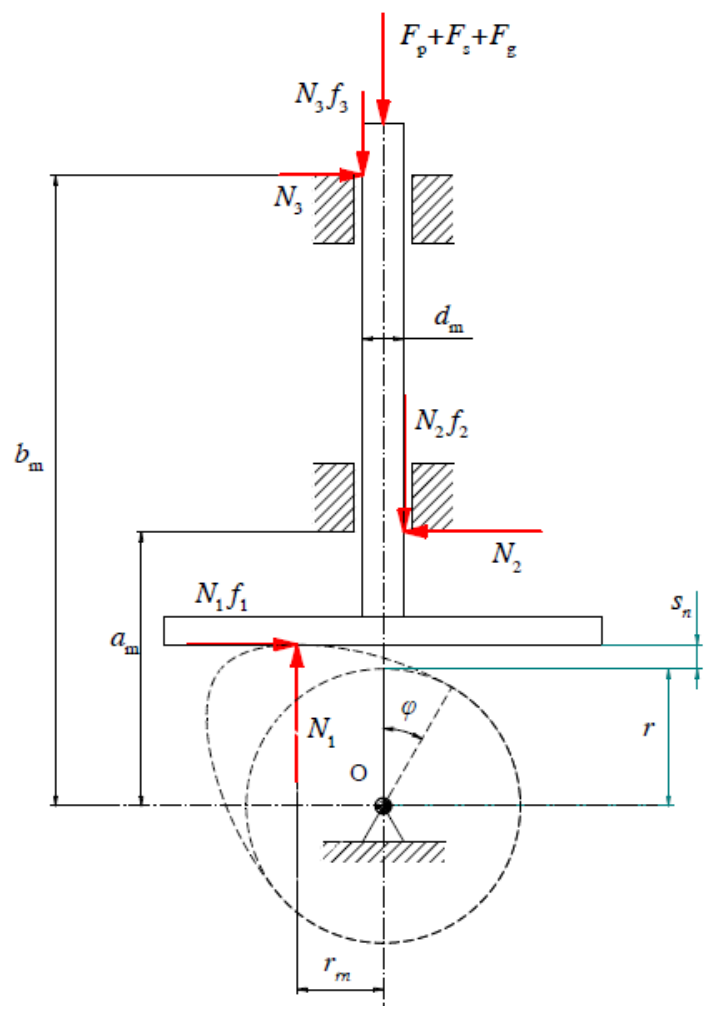

Fig. 2. Relaxed tappet

$$
F_{\mathrm{p}}=\frac{G \cdot d_{\mathrm{p}}^{4}}{8 n_{\mathrm{p}} \cdot D_{\mathrm{p}}^{3}}\left(s_{n}+y_{1}\right)
$$

where $G[\mathrm{~Pa}]$ is the shear modulus, $d_{p}[\mathrm{~m}]$ the diameter of the wire from which the spring is made, $D_{p}[\mathrm{~m}]$ the pitch diameter of the spring, $n_{p}[1]$ is the number of active coils of the spring and $y_{1}[\mathrm{~m}]$ a longitudinal spring bias. The weight of the plunger and materials related to it is given by equation (14).

$$
F_{\mathrm{g}}=m_{\mathrm{z}} \cdot g
$$

where $m_{z}[\mathrm{~kg}]$ is the mass of the plunger and materials related to it , and $g\left[\mathrm{~m} / \mathrm{s}^{2}\right]$. Inertia force of the tappet and the masses attached to it is given by (15).

$$
F_{\mathrm{s}}=m_{\mathrm{z}} \cdot a_{n}
$$

where $a_{n}\left[\mathrm{~m} / \mathrm{s}^{2}\right]$ acceleration tappet which is given as the second derivative of the polynomial stroke curve (3), i.e. equation (16). 


$$
a_{n}=\omega_{\mathrm{k}}^{2} \sum_{i=\frac{n+1}{2}}^{n} i(i-1) \alpha_{i} \cdot \phi^{i-2}
$$

where $\omega_{k}[\mathrm{rad} / \mathrm{s}]$ is a constant angular velocity of rotation of the camshaft. The aforementioned configuration of the cam mechanism, we can say that the place planar motion. The body of the plane has three degrees of freedom. To show unambiguously describe equilibrium tappet is thus sufficient force equation in two axes and one torque equation. Force balance at the horizontal axis (an imaginary $x$-axis) can be described by the following equation.

$$
N_{1} \cdot f_{1}-N_{2}+N_{3}=0
$$

By considering the d'Alembert's principle, we can build a relationship describing the balance of the tappet in the vertical axis (imaginary axis $y$ ).

$$
-F_{\mathrm{p}}-F_{\mathrm{s}}-F_{\mathrm{g}}+N_{1}-N_{2} \cdot f_{2}-N_{3} \cdot f_{3}=0
$$

The balance of moments of force acting on the plunger is related to the rotational axis of the cam and is given by equation (19).

$$
-N_{1} \cdot f_{1}\left(s_{n}+r\right)-N_{1} \cdot r_{\mathrm{r} n}-N_{2} \cdot f_{2} \frac{d_{\mathrm{m}}}{2}+N_{2} \cdot a_{\mathrm{m}}-N_{3} \cdot b_{\mathrm{m}}+N_{3} \cdot f_{3} \frac{d_{\mathrm{m}}}{2}=0
$$

Given the relative size of individual members can be ignored $N_{2} \cdot f_{2}\left(d_{\mathrm{m}} / 2\right)$ and $N_{3} \cdot f_{3}\left(d_{\mathrm{m}} / 2\right)$. Equation (19) is then reduced to form (20).

$$
-N_{1} \cdot f_{1}\left(s_{n}+r\right)-N_{1} \cdot r_{\mathrm{r} n}+N_{2} \cdot a_{\mathrm{m}}-N_{3} \cdot b_{\mathrm{m}}=0
$$

We solve the three equations in three unknowns (17), (18) and (20). Expressing $N_{3}$ from the equation (17) and substituting into the remaining two equations (18) and (20) we obtain the system of two equations (21) and (22) with two unknowns.

$$
\begin{gathered}
-F_{\mathrm{p}}-F_{\mathrm{s}}-F_{\mathrm{g}}+N_{1}-N_{2} \cdot f_{2}-\left(N_{2}-N_{1} \cdot f_{1}\right) f_{3}=0 \\
-N_{1} \cdot f_{1}\left(s_{n}+r\right)-N_{1} \cdot r_{\mathrm{r} n}+N_{2} \cdot a_{\mathrm{m}}-\left(N_{2}-N_{1} \cdot f_{1}\right) b_{\mathrm{m}}=0
\end{gathered}
$$

By multiplying the brackets, we obtain a set of equations (23) and (24).

$$
\begin{gathered}
-F_{\mathrm{p}}-F_{\mathrm{s}}-F_{\mathrm{g}}-N_{2} \cdot f_{3}+N_{1} \cdot f_{1} \cdot f_{3}-N_{2} \cdot f_{2}+N_{1}=0 \\
-N_{2} \cdot b_{\mathrm{m}}+N_{1} \cdot f_{1} \cdot b_{\mathrm{m}}+N_{2} \cdot a_{\mathrm{m}}-N_{1} \cdot f_{1}\left(s_{n}+r\right)-N_{1} \cdot r_{\mathrm{r} n}=0
\end{gathered}
$$

Expressing $N_{2}$ from the equation (23), subsequent substitution into equation (24) and adjustments we obtain equation (25) describing the axial force $N_{1}$ between the cam and the tappet.

$$
N_{1}=\frac{\left(F_{\mathrm{p}}+F_{\mathrm{s}}+F_{\mathrm{g}}\right) \cdot\left(b_{\mathrm{m}}-a_{\mathrm{m}}\right)}{f_{1} \cdot f_{3} \cdot b_{\mathrm{m}}+b_{\mathrm{m}}-f_{1} \cdot b_{\mathrm{m}}\left(f_{3}+f_{2}\right)-f_{1} \cdot f_{3} \cdot a_{\mathrm{m}}-a_{\mathrm{m}}+f_{1}\left(s_{n}+r\right)\left(f_{3}+f_{2}\right)+r_{\mathrm{r} n}\left(f_{3}+f_{2}\right)}
$$

The size of arm of force $r_{1 n}$ varies depending on the rotation angle of the cam. Figure 3 are shown the geometrical relations. According to Newton's law of action and reaction from acting on the cam follower force $N_{1}$ and the cam follower on the same reverse force.

$$
w_{n}^{2}=\left(r+s_{n}\right)^{2}+r_{\mathrm{r} n}^{2} \rightarrow r_{\mathrm{r} n}=\sqrt{w_{n}^{2}-\left(r+s_{n}\right)^{2}}
$$


where $r[\mathrm{~m}]$ is the radius of the basic circle and $w_{n}[\mathrm{~m}]$ the cam profile equations in polar coordinates, that was derived in [2]. The size of arm strength $r_{1 n}$ is therefore expressed by the equation (27).

$$
r_{\mathrm{r} n}=\sqrt{\left(\left(s_{n}+r\right) \cdot \cos ^{-1}\left(\operatorname{arctg}\left(\frac{\mathrm{d} s_{n}}{\mathrm{~d} \phi} \frac{1}{s_{n}+r}\right)\right)\right)^{2}-\left(r+s_{n}\right)^{2}} .
$$

Torque balance to the axis of cam rotation is given by equation (28).

$$
-M+N_{1} \cdot r_{\mathrm{r} n}+N_{1} \cdot f_{1}\left(s_{n}+r\right)=0 .
$$

Torque which is needed to bring the cam shaft to rotate the cam constant angular speed $\omega_{k}$, is given by equation (29)

$$
M=N_{1}\left(r_{\mathrm{r} n}+f_{1}\left(s_{n}+r\right)\right)
$$

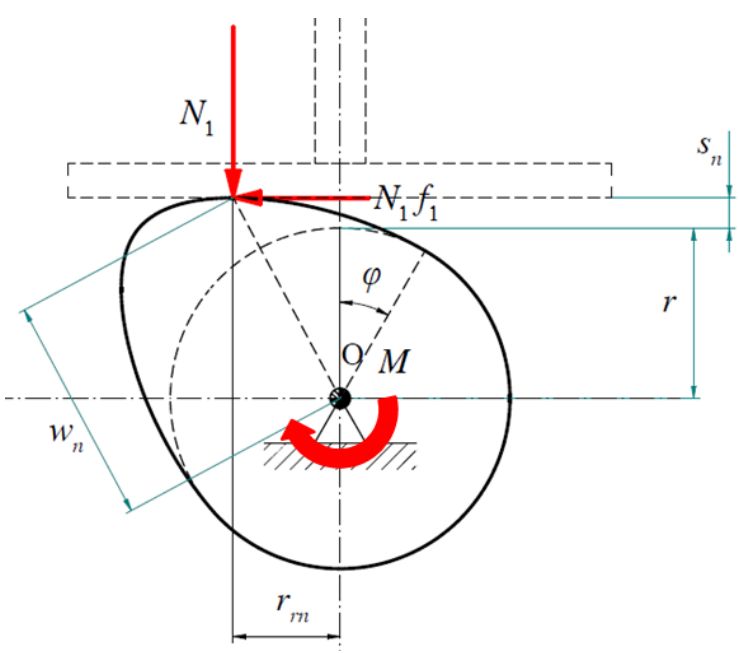

Fig. 3. Release of the cam

\section{Torque specific mechanism}

The following table lists the specific parameters of the cam mechanism. These are the parameters of the measuring stations, a draft of which has been the subject of previous work on this issue.

Table 1. Values of specific mechanism

\begin{tabular}{|l|l|l|}
\hline Parameter & Unit & Description \\
\hline$n=9$ & {$[1]$} & $\begin{array}{l}\text { lifting dependence degree of the polynomial (odd } \\
\text { integer) }\end{array}$ \\
\hline$\phi_{2}=\pi / 2$ & {$[\mathrm{rad}]$} & $\begin{array}{l}\text { the angle of connection of the cam profile on the base } \\
\text { circle }\end{array}$ \\
\hline$z=0.01$ & {$[\mathrm{~m}]$} & stroke \\
\hline$r=0.05$ & {$[\mathrm{~m}]$} & the radius of the base circle \\
\hline$\omega_{\mathrm{k}}=149.2257$ & {$[\mathrm{rad} / \mathrm{s}]$} & $\begin{array}{l}\text { angular velocity (equivalent to 1425 revolutions per } \\
\text { minute) }\end{array}$ \\
\hline
\end{tabular}




\begin{tabular}{|c|c|c|}
\hline$y_{1}=0.01$ & {$[\mathrm{~m}]$} & linear spring preload \\
\hline$G=7.9 \cdot 10^{10}$ & {$[\mathrm{~Pa}]$} & shear modulus of the material of the spring \\
\hline$d_{\mathrm{p}}=0.005$ & {$[\mathrm{~m}]$} & diameter of the spring wire \\
\hline$D_{\mathrm{p}}=0.025$ & {$[\mathrm{~m}]$} & mean spring diameter \\
\hline$n_{\mathrm{p}}=12.5$ & [1] & number of active coils of the spring \\
\hline$f_{1}=0.1$ & [1] & $\begin{array}{l}\text { the coefficient of friction between the cam and the } \\
\text { tappet }\end{array}$ \\
\hline$f_{2}=0.1$ & [1] & $\begin{array}{l}\text { the coefficient of friction between the tappet and } \\
\text { leadership } 1\end{array}$ \\
\hline$f_{3}=0.1$ & [1] & $\begin{array}{l}\text { the coefficient of friction between the tappet a } \\
\text { leadership } 2\end{array}$ \\
\hline$a_{\mathrm{m}}=0.2$ & {$[\mathrm{~m}]$} & Length of fig. 2 \\
\hline$b_{\mathrm{m}}=0.7$ & {$[\mathrm{~m}]$} & Length of fig. 2 \\
\hline$c_{\mathrm{m}}=0.04$ & {$[\mathrm{~m}]$} & Length of fig. 2 \\
\hline$m_{\mathrm{z}}=0.6$ & {$[\mathrm{~kg}]$} & weight lifters and materials related to it \\
\hline
\end{tabular}

The following figure shows the torque waveform of the stroke for the parameters given in tab. 1 . The graph 4 is constructed based on the above theory.

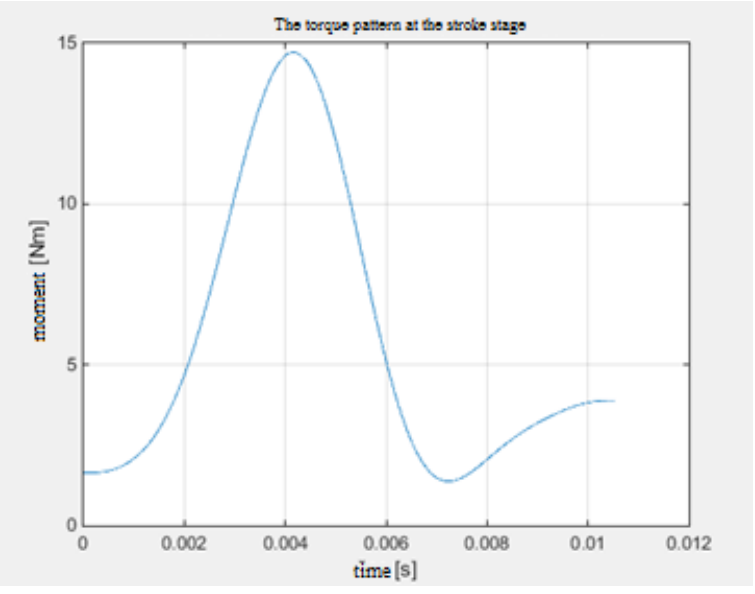

Fig. 4. Torque curve

\section{Conclusion}

Was developed a method of creating stroke dependency. Stroke dependence is generated based on the desired stroke of polynomial degree and angle of connection of the cam profile on the base circle. The degree of the polynomial is expressed by an odd natural number. The method of release was expressed by the normal force between the cam and the tappet. Subsequently, it was determined the course of torque. What is given greater degree polynomial, it is a requirement for minimum theoretical base circle radius larger (the result of previous work). Where certain basic circle radius is sufficiently large so that it is possible without changing the radius increasing degree polynomial (in a certain range), the higher degree polynomial increases as the maximum torque value. 
This contribution was created in support of project SG 48202150004 01/2016 at UJEP.

\section{References}

1. H. A. Rothbart, Cam design handbook. (The McGRAW-HILL Companies. Inc., 587 p., 2004)

2. P. Hejma, M. Svoboda, J. Kampo, J. Soukup, Analytic analysis of a cam mechanism. Procedia Engineering 177, 3-10 (2017)

3. R. G. Budynas, Shigley's Mechanical Engineering Design. $\left(8^{\text {th }}\right.$ ed. in SI Units, The McGraw-Hill Companies. Inc., 2008)

4. S. Borkowski, Toyotarity. Innovations. Improvement. (Polski Instytut Jakości sp.z o.o., 190 p., 2016)

5. M. Apetaur, F. Klimenda, Mechanika výrobních strojů. Manipulátory a průmyslové roboty. (1. vydání, 95 p., 2014)

6. R. Křižík, K. Weigner, J. Svoboda, Stavba a provoz stroju III Mechanizmy. (SNTL Nakladatelství technické literatury, 1983)

7. P. Hejma, F. Klimenda, J. Kampo, Návrh profilu vačky. (Dynamika tuhých a deformovatelných těles, 2015)

8. I. Blanco, V. Diaz, J., L., P. Cam design. (Universidat Carlos III, Madrid, 2005) 